\title{
Serviço Social e tendências teóricas atuais
}

\section{José Fernando Siqueira da Silva}

Universidade Estadual Paulista (UNESP) e Universidade Federal

de São Paulo (UNIFESP)

\section{Serviço Social e tendências teóricas atuais}

Resumo: $\mathrm{O}$ artigo propõe um debate sobre as atuais tendências teórico-metodológicas do Serviço Social brasileiro. Analisa a tensa, contraditória e necessária relação entre o Serviço Social brasileiro, a teoria social de Marx e a tradição marxista, destacando duas importantes categorias gramscianas: intelectuais e direção-cultural.

Palavras-chave: Serviço Social. Crítica. Intelectuais. Direção cultural.

\section{Social Service and Current Theoretical Trends}

Abstract: This article debates current theoretical-methodological trends found in Brazilian social service. It analyzes the tense, contlictory and necessary relationship between Brazilian social service, Marxist social theory and the Marxist tradition, highlighting twimportant Gramscian categories: intellectuals and cultural-direction.

Keywords: Social Service. Criticism. Intellectuals. Cultural direction. 


\section{Direção cultural, intelectuais e Serviço Social}

A influência de Antonio Gramsci no Serviço Social brasileiro é significativa, vasta e diversa. Merece observações críticas não necessariamente vinculadas à rica e original contribuição do pensador e militante marxista italiano, mas às diversas formas de apropriação de seu legado no tratamento de questões mais diretamente vinculadas à profissão. Há seguramente, leituras e incorporações riquíssimas, cuidadosamente trabalhadas que convivem com problemáticas generalizações. Valorizar os ganhos e criticar os limites deste debate no interior da categoria profissional dos assistentes sociais é procedimento necessário para não alimentar a decadência ideológica (LUKÁCS, 1981) em curso também nas ciências humanas e sociais:

pode-se dizer que Gramsci, de certo modo, desloca o tratamento prioritário dado por Marx à economia (certamente a ciência particular com a qual esse último mais de confrontou), transferindo-o para a sociologia e, muito particularmente, para a ciência política. E Gramsci fez essa opção porque partiu do pressuposto - o que pode ser facilmente confirmado pela leitura dos Cadernos do Cárcere - de que a crítica da economia política já havia sido feita: ele aceita integralmente os resultados dessa critica, tanto os produzidos pelo próprio Marx quanto, e talvez sobretudo, os contidos nos desenvolvimentos que ela encontrou na obra de Lenin, particularmente em O Imperialismo fase superior do capitalismo (...). Tratava-se assim, para prosseguir o trabalho crítico iniciado por Marx, de estendê-lo a novos âmbitos da totalidade social (COUTINHO, 1996, p. 102).

Todavia, a preocupação de Gramsci em reafirmar a crítica à economia política de Marx, desenvolvendo temas mais afeitos à sociologia e à política, considerando o avanço das ciências especializadas, não pode ser confundida com certo tipo de fragmentação que desconsidera a categoria da totalidade, fundamental para o autor marxista italiano, e destaca sua face política e sociológica Encontra-se aqui um dos mais sérios equívocos cometidos na apropriação da rica obra gramsciana - grande parte escrita no cárcere na luta contra o fascismo - que desloca e distingue a contribuição de Gramsci do trabalho crítico empreendido por Marx, destacando suas diferenças e suas partes úteis à atualidade. Salientar a não identidade entre eles não significa, em hipótese alguma, negar a unidade de uma tradição marxista seguramente diversa, submetida a desafios específicos, a tempos históricos diversos vinculados a particularidades nada desprezíveis, como o contexto italiano vivido por Gramsci. Não é por acaso que complexas categorias gramscianas imersas na luta de classes empreendidas no capitalismo de seu tempo, na organização revolucionária, ambas inseparáveis da crítica à economia política sustentada nos pressupostos marxianos (estado-sociedade civil, hegemonia, correlação de forças, bloco histórico, intelectuais, direção sociocultural, entre outros), são separadas deste contexto e pragmaticamente aplicadas a outros cenários e realidades sem o devido rigorNão é objetivo de este artigo analisar a complexidade desta problemática em tão poucas linhas, ainda que seja oportuno indicar alguns cuidados sobre isto para o Serviço Social e a pertinência de Gramsci para a crítica aos neoconservadorismos $\quad{ }^{2}$. Para tanto, serão consideradas, aqui, como componentes da totalidade social, duas categorias gramscianas importantes na relação direta com o Serviço Social brasileiro: intelectuais e direção cultural

Para Gramsci a categoria intelectual forma-se na história e na historicidade, ou seja, vincula-se à divisão social do trabalho burguesa em dado momento e às condições por ela objetivamente dadas. É neste contexto contraditório que os intelectuais se constituem como tais. O marxista italiano lembra que "ölos os homens são intelectuais, mas nem todos os homens têm na sociedade a função de intelectuais" (GRAMSCI, 2000, p. 18). Destaca, para tanto, duas formas principais de intelectuais: a) os orgânicos, ou seja, aqueles que se vinculam à classe social e ajudam a organizar as ideias desta classe, difundi-las, torná-las culturalmente hegemônicas; b) os tradicionais, assim denominados por estarem vinculados organicamente a instituições de tradição e de peso social, tais como as universidades, as igrejas, entre outros espaços ${ }^{3}$. A partir desta categorização, Gramsci constrói uma orientação bastante dinâmica sobre a intelectualidade: tanto os intelectuais orgânicos como os tradicionais podem ser reacionários, conservadores ou revolucionários, todos eles assentados sobre determinado momento histórico, lidando com as condições objetivas por ele impostas, atuando na construção de direções sociais hegemônicas no processo de luta de classes que podem formar blocos históricos capazes de influírem na sociedade seja para mantê-la ou para transformá-la ${ }^{4}$. Gramsci (2007a, p. 35) delimita sua base dialéticomaterialista ao tratar da política:

O político em ato é um criador um suscitador, mas não cria a partir do nada nem se move na vazia agitação de seus desejos e sonhos.Toma como base a realidade efetiva: mas o que é esta realidade efetiva? Será algo estático e imóvel, ou, ao contrário, uma relação de forças em contínuo movimento e mudança de equilíbrio? Aplicar a vontade à criação de um novo equilíbrio das forças realmente existentes e atuantes, baseando-se 
naquela determinada força que se considera progressista, fortalecendo-a para fazer triunfąıignifica continuar movendo-se no terreno da realidade efetiva, mas para dominá-la e superá-la (ou contribuir para isso).

É neste contexto, e inseparável dele, que o fundador do partido comunista italiano destaca a importância da construção da hegemonia como direção cultural, no campo da práxis social, da luta de classes. É neste cenário que salienta a importância da política, como grande política, como arte do convencimento, da articulação no calor da luta, como espaço de formação de consciência de classe que estimula a filosofia da práxis em um processo catártico, ético-político, que unifica, sem identificar, o objetivo e o subjetivo, o individual e o coletivo: "Pode-se empregar a expressão 'catarse' para indicar a passagem do momento meramente econômico (ou egoístico-passional) ao momento ético-político, isto é, a elaboração superior da estrutura em superestrutura na consciência dos homens. Isto significa, também, a passagem do 'objetivo ao subjetivo' e da 'necessidade à liberdade"” (GRAMSCI, 2001, p. 314).

O denominado Projeto Ético-Político Profissional do Serviço Social, no Brasil, possui uma clara inspiração maxista-gramsciana, ainda que contenha outras tendências marxistas. Ele se sustenta na construção de uma hegemonia no campo profissional, entendida como direção social estratégica, que a vincula a projetos societários amplos comprometidos com uma posição, de partida, anticapitalista progressista e de afirmação de direitos no campo básico, mínimo, da seguridade social. A lei de regulamentação da profissão, o Código de Ética dos assistentes sociais e as diretrizes curriculares, com todas as alterações que esta ultima sofreu desde sua formatação original, preconizam a defesa intransigente de direitos fundamentais, uma formação profissional generalista e crítica e um trabalho profissional afinados, em tese, com tais orientações. Neste contexto há o claro compromisso em formar intelectuais capazes de pensar e intervir criticamente nas refrações da questão social ${ }^{5}$.

Todavia, os conservadorismos e neoconservadorismos também necessitam ser explicados a partir de suas mediações com o Serviço Social, considerando as particularidades da realidade brasileira marcada por uma revolução burguesa realizada pela via colonial, por isto hipertadia, edificada sobre as bases do capitalismo dependente (FERNANDES, 1987; 2009). O Serviço Social, como profissão em escala mundial, assentou-se em "tradições antimodernas (não apenas de perfil católico), com uma forte perspectiva anticapitalista romântica, defensora de valores e princípios devastados pela revolução burguesa consolidada", mas também, ao mesmo tempo, articulou-se a orientações modernas que promoveram a aproximação entre o pensamento conservador e a defesa da sociedade do capital já no início do século 19. "Acomodam-se, ai, "valores humanitários', o manejo de abordagens científicas e a manutenção da ordem do capital, adensando e modernizando essa tendência ao longo de todo século 20" (SILVA, 2015, p. 110).

Mesmo considerando o legado crítico e progressista do Serviço Social brasileiro gradativamente formado nos últimos 40 anos, as limitações atuais são enormes. Elas não podem ser subestimadas e têm se adensado seja no campo da formação ou do trabalho profissional do assistente social. São limites objetivos que não poderão ser enfrentados somente com boas intenções. Mais do que isto, este legado vem sendo questionado por diversos caminhos, com diferentes discursos, mais ou menos conscientes, muito deles sutis, não explícitos e quase sempre sustentados em nome da crítica, da defesa da prática profissional e de suas genuínas demandas como critério principal.

\section{Tendências teóricas em curso no Serviço Social brasileiro: direção cultural e formação de intelectuais}

Netto (1996, p. 117), na segunda metade dos anos 1990, já destacava o que estaria no centro da polêmica profissional daquela década em diante: "manter , consolidar e aprofundar a atual direção estratégica ou contê-la, modificá-la e revertê-la". Naquela oportunidade, analisando o impacto da reestruturação produtiva neoliberal em escala planetária ${ }^{6}$, destacou que o Serviço Social brasileiro, mais especificamente, seu legado crítico, estava sendo colocado à prova. Retomando as perspectivas analíticas que nasceram a partir da renovação da profissão no Brasil, no bojo do processo de reconceituação do Serviço Social latino-americano, Netto (1991) analisa densamente os possíveis desdobramentos das vertentes teóricas. Foi exatamente neste período que o Serviço Social brasileiro materializou a base de sua direção social estratégica conhecida, no interior desta profissão, como Projeto Ético-Político Profissional.

Destacando a necessidade de considerar possíveis intersecções entre as vertentes que já se objetivavam com certa intensidade na segunda metade dos anos 1990, Netto (1996) destacou cinco possibilidades: a) a continuidade e o aprofundamento da vertente reconceituada denominada como intenção de ruptura, de cariz marxista; b) o aprofundamento da perspectiva modernizadora, de forte perfil tecnocrático; c) a continuidade, 
sem presença intensa, da reatualização do conservadorismo, de inspiração fenomenológica; d) o desenvolvimento e o adensamento de uma vertente neoconservadora, de forte base epistemológica pós-moderna; e) o florescimento de linhas aparentemente radicais valorizadoras de experiências que brotam da realidade sem a necessidade da teorização e da pesquisa rigorosa e sistemática. Insistindo na possibilidade real de sobreposição e intersecção de elementos mais próximos de uma ou outra vertente, Netto (1996, p. 126) chama a atenção para a presença mais intensa das orientações a, b e d, como as que travariam o "confronto teórico-profissional" mais substantivo, e pontua os paradigmas de profissionais que tais tendências tenderiam a reforçar:

Em resumo, confrontam-se dois 'paradigmas' de profissionais: o técnico bem adestrado que vai operar instrumentalmente sobre as demandas do mercado de trabalhđal como elas se apresentam ou o intelectual que, com qualificação operativa, vai intervir sobre aquelas demandas a partir de suæompreensão teóricocrítica, identificando a significação, os limites e as alternativas da ação focalizada.

Netto acertou, no geral, nas projeções feitas em 1996, seja em relação ao perfil das vertentes teóricas, seja em relação àquelas que disputariam mais intensamente um espaço no cenário real. Mais do que isto, apontou pertinentemente o que estava (e está) no centro do debate: afirmar ou não a tendência estratégica dos anos 1990 ou negá-la; formar intelectuais ou técnicos adestrados, e isto também remete à discussão de Gramsci. Trata-se de uma observação absolutamente atual, nevrálgica, ainda que seja fundamental revelar as mediações sócio históricas, nada desprezíveis, que têm se apresentado nos últimos 20 anos. É preciso reconhecer a existência de um ataque frontal, sistemático e contínuo à formação profissional pretendida pela direção estratégica dos anos 1990, bem como os inúmeros e complexos impactos relacionados tanto com questões vinculadas ao ensino superior, em que o ensino a distância é um dos temas centrais, como também com as determinações do mercado de trabalho e seus desdobramentos atuais (BRAZ; RODRIGUES, 2013).

Considerando a análise sócio histórica aqui esboçada e retomada a partir das certeiras observações tecidas por Netto na segunda metade dos anos 1990 (claramente orientandas pelo ponto de vista ontológico de inspiração lukacsiana), a continuidade desta reconstrução sustentada nas determinações e mediações atualmente postas é um exercício crucial. Perseguir essa trama material como "lógica da coisa" (MARX, 2005, p. 39), ou seja, como um processo edificado na luta concreta, objetivamente dada, com uma dinâmica própria que se objetiva para além das mentes pensantes (não plenamente controlada por seus combatentes seja individualmente ou coletivamente), é uma empreitada necessária para manter a crítica acesa. A atenção, aqui, se concentrará nas vertentes a, b e d, há pouco citadas, nas condições objetivas impostas pela década de 1990, procurando adensá-las neste espaço temporal de 20 anos (1996-2016) sem desconsiderar a possível, mas não necessária, intersecção entre elas.Tais perspectivas não podem ser explicadas a partir de uma leitura endógena do Serviço Social, como se tais vertentes fossem produzidas unicamente no interior da profissão, bem como não devem ser tomadas como blocos estanques, não dinâmicos. Também por isto, recupera as preocupações gramscianas com as expressões do conservadorismo, destacando a importância de criticá-las como direção cultural hegemônica produtora de certa intelectualidade responsável pela organização e propagação de teses e marcos teóricos específicos que não se limitam ao universo interno do Serviço Social.

A vertente originalmente denominada por Netto $(1991 ; 1996)$ como modernizadora possui um eixo estruturante que hoje a define como fiel depositária do legado modernizador: a integração empreendedora dos indivíduos. Seu cariz tecnocrata denuncia o profissional a ser formado: o técnico bem adestrado, aqui entendido como aquele que deve conhecer o necessário para sistemicamente e criativamente operar o instituído, dinamicamente adaptado às fronteiras institucionais A ênfase na integração social, de forte base positivista/funcionalista, inspirada em temas abordados densamente por Durkheim (disfunção social, solidariedade mecânica e orgânica, patologias sociais, entre outros) e por parte do funcionalismo norte-americano (particularmente nos estudos sobre as funções e papéis sociais (Parsons e Merton), que esteve presente nesta vertente desde sua versão mais elementar no âmbito do Serviço Social renovado, originalmente apresentadas nos documentos dÁraxá e Teresópolis no final dos anos $1960^{7}$, se renova e se adensa. A inovação e a modernização desta tendência no âmbito do Serviço Social brasileiro nos dias atuais aparecem na ênfase empreendedora desta integração dinâmica, solidária, processo este viabilizado por meio de certo tipo de empoderamento centrado nos indivíduos e em seus dotes pessoais, ressaltando traços nitidamente meritocráticosApresenta-se, aqui, outro traço marcante desta vertente: a subserviência absoluta da profissão e dos profissionais à ordem social em curso, ou seja, à ordem do capital. Não há, neste caso, obviamente, qualquer tipo de indagação estrutural sobre a ordem burguesa e suas regras, eternizadas e naturalizadas, embora haja, eventualmente, o reconhecimento da existência de suas inevitáveis tensões causadas por desarranjos momentâneos racionalmente e tecnicamente administrados. Mas esta vertente vai além e desenvolve importantes intersecções com o item d), identificado por Netto (1996) e denominada de vertentes neoconservadoras e pós-modernas . Trata-se de uma necessidade objetiva desta 
orientação no seu afã modernizador ou seja, uma imposição real voltada a responder contradições ontológicas contidas no mundo do capital que esta tendência toma como eterna, seguindo a tradição durkheiminiana de que as revoluções são tão impossíveis como milagres. Como dito há pouco, o faz com uma particularidade importante: total subserviência à ordem em curso no sentido de aceitar e reforçar suas teses centrais. Trata-se, no limite, de um problema de gestão que deve contar com bons gestores das tensões sociais possíveis de serem eternamente administradas. O possível a ser feito se reduz às fronteiras institucionais, vulgarmente e forçadamente adaptados, quanto muito e formalmente, ao Projeto Ético-Político Profissional dos anos 1990, sem qualquer relação e conexão com ele.

O método, claro, não poderia ser outro para esta tradição: o sistêmico inspirado, sobretudo, em fragmentos dos estudos de Bertalanffy (1980) e de Capra (2004). Esta tradição articula, com maestria, modernização das teses positivista/funcionalistas, neoconservadorismo, sociedade do capital e sua gestão responsável, aperfeiçoando a noção do todo articulado em subsistemas e reconhecendo o sentido positivo dos conflitos e dos desiquilíbrios, bem como reedita várias formas de relativismo e de ecletismo desde que descartando e combatendo o mal marxista. É neste contexto que temas e autores pós-modernos e neoconservadores, em diferentes medidas, são fartamente utilizados na gestão da nova questão social por meio de um novo contrato social (ROSANVALLON 1995), no trato das metamorfoses da questão social (CASTEL, 1998) ou, ainda, a análise do processo de exclusão-inclusão social, a desigualdade latino-americana, a explosão da insegurança urbana, destacando a dimensão ética de tais tensões e o desenvolvimento das capacidades dos indivíduos todos eles comprometidos em lidar com novos desarranjos (SEN, 1999). Há momentos, todavia, que a tara regressiva da vertente modernizadora encontra interlocutores genuínos, fartamente utilizados no campo da assistência social, que relativizam direitos ao mesmo tempo em que afirmam e eternizam a economia-política burguesa. Destaca, por exemplo, BECK (1998, p. 42): "las sociedades de riesgo no son sociedades de clases; sus situaciones de peligro no se pueden pensar como situaciones de clases, ni sus conflictos como conflictos de clases".

O que esperar da formação profissional neste nível? Nada mais do que o técnico operativo, bem adestrado tecnicamente e, claro, teoricamente naqueles elementos considerados essenciais para operar os tempos pós-modernos. A formação universitária não poderá ultrapassar o essencialmente necessário, valorizando o estudo dito plural, transclassista (IAMAMOTO, 1985; 2007), reeditando o comando técnico-operacional e a verdade última da intervenção profissional-social, seus desafios imediatos, sobre uma base teórica pobre e subserviente, pragmaticamente instrumentais e descritivas:

\begin{abstract}
Os conteúdos de economia, de política, de história e de filosofia são pontualmente recuperados, reforçando uma economia 'econômica' e economicista (desprovida totalmente de economia-política), uma política 'dita a-política' (no seu limite 'responsável'), uma 'história' a-histórica (...). Em contraposição, sugere-se uma 'ciência' não ontológica, sustentada em procedimentos 'qualitativos' e quantitativos responsáveis pelo tratamento equilibrado, 'científico', que impõe uma lógica estranha, externa à própria realidade. Tudo isto submetido às demandas imediatamente postas à profissão no campo da 'prática profissional', que não suporta reflexões críticas 'desnecessárias', 'abstratas' e 'distantes da realidade' enfrentadas pelos profissionais de Serviço Social (SILVA, 2015, p. 116).
\end{abstract}

Debrucemo-nos, todavia, ainda que sinteticamente, na análise dos traços predominantes na vertente d, ou seja, aquela que genuinamente sustenta suas bases no campo da chamada pós-modernidade. Guardadas as intersecções com a perspectiva anterior, sobretudo o manuseio de autores similares e o debate de teses próximas, a "nova questão social", o "novo contrato social", o processo de exclusão-inclusão, a inexistência, relativização ou insuficiência das classes sociais, esta tendência não se identifica com a anterior Suas teses e respostas centrais são diversas daquelas defendidas enfaticamente pela vertente modernizadora. A ênfase, aqui, não está propriamente na subserviência consciente à ordem do capital, como a ordem a ser afirmada e defendida, mas na resignação assumida diante dela valorizando seus pontos positivos e negativos, destacando a centralidade do indivíduo nos jogos de linguagens tecido no campo social-cibernético (LYOTARD, 2000). Esta tendência que vem se objetivando no Serviço Social brasileiro na atualidade, não põe seu foco na integração empreendedora como base central, mas em uma forma para afirmar direitos com base nas lutas empreendidas nos micros espaços por segmento, na inclusão participativa dos indivíduos excluídos, seu empoderamento, na participação política em si e no seu modelo emancipatório focal e estrit@ lado mal do capitalismo deve e pode ser humanizado, corrigido e ajustado com base nas instâncias participativas centradas em espaços territoriais definidos, nas demandas locais não classistas, conselhos, comissões, grupos formados por afinidades, entre outros. A ênfase dita participativa e comunitária, em si, se descola de sua relação gânica com o Estado, como seguridade social, como políticas sociais tecidas no processo de luta de classes, fragmentando-se em lutas sociais isoladas e por segmento, contra o Estado opressor e a burocracia institucional. É neste contexto que os 
direitos podem ser garantidos, ou seja, por meio da organização local, por subgrupos específicos, por bairrơ, como lutas sociais cotidianas empreendidas como uma onda de protestos locais ou por segmento, não classista, que cresce espontaneamente tendo na ação do indivíduo e na sua liberdade o foco central sem qualquer projeção futura (como utopia possível). Sendo assim, o Projeto Ético-Político da Profissional do Serviço Social, como direção social estratégica, tende a ser visto como uma especulação utópica e sem sentido.

Seguramente a pós-modernidade, enquanto orientação geral, não é um fenômeno novo. Sua presença se fez sentir mais diretamente nos anos 1970 no mesmo período em que o receituário ultraliberal de Hayek (18991992) e Friedman (1912-2006) se objetivou como paradigma para as economias capitalistas mundiais. São considerados expoentes da pós-modernidade autores como Lyotard (2000) e a sociedade como uma rede de comunicação linguística, Foucault $(1993 ; 1994)$, contrário a perspectivas centradas na categoria da totalidade e formulador de uma noção de poder horizontal, microssocial e fragmentado - precursor de ações locais, pontuais e não classistas -, além de muitos outros autores que trataram ou tratam diversamente de diferentes temas:

\section{O que esperar da formação}

\section{profissional neste nível? Nada} mais do que o técnico operativo, bem adestrado tecnicamente e, claro, teoricamente naqueles elementos considerados essenciais para operar os tempos pós-modernos. Derrida (1991), Baudrillard (2008), Maffesoli (2003; 2007), Souza Santos (1992), Morin (2015), entre outros. Tais autores reconhecem certo nível de desiquilíbrios no funcionamento da ordem em curso, oferecem miradas interessantes sobre determinados temas, mas seguramente reeditam traços conservadores-modernos, entendidos como pós-modernos, seja em relação ao seu método de trabalho, seja em relação às suas preocupações ideopolíticas ou crítico-resignadas à ordem em curso. O método de estudo, neste caso, tende a reafirmar, não homogeneamente, uma tradição compreensiva inspirada no legado weberiano, não necessariamente em relação a seus tipos ideias (WEBER, 1986), mas ressaltando diversas teorias que destacam a ação social localista e a crítica estatal-burocrática que resgatam certo tipo de logicismo claramente anti-ontológico, negador da modernidade como pós-modernidade, como superação das metanarrativas, das grandes teorias sociais e das grades lutas, oposições e conflitos nos campos político, filosófico, social e cultural-artístico. Não se trata, propriamente, de desconsiderar o plano ontológico, mas de submetê-lo a certo tipo de especulação logicista, comandada pela liberdade criativa dos indivíduos livres e isolados, que retoma a fragmentação, a flexibilização e a subjetivização da ciência, na esteira da razão subjetiva de Katht impondo à realidade leituras fragmentadas e ecléticas sobre o movimento do real, como coisas das lógicas que jogam o jogo das interpretações e das linguagens, vistas como verdadesA confusão aqui é precisa: leituras sobre o real são vistas como as verdades do real, negando uma lógica do próprio real que independe da consciência e do conhecimento sobre ele. A defesa da fragmentação das lutas reais segue a fragmentação proposta no campo da especulação da teoria do conhecimento, gerando certo tipo de "decadência ideológica" (LUKÁCS, 1981, p. 109) logicista e subjetivista. Não se trata de formar um profissional de Serviço Social unicamente técnicooperativo no seu sentido estrito, como na vertente anterior, mas de valorizar a teoria, o estudo e a pesquisa a partir de parâmetros que reeditam certa ciência abstrata como intelectuais rebeldes-especulativos, que põem em prática sua criatividade individual para criticar modelos, regras, orientações gerais, instâncias limitadoras da liberdade individual, predominantemente presentes nas diversas instituições e no Estado tomando-os como espaços autoritários e centralizadores em si, sem precisar sua concretude sócio-histórica e seu caráter classista.

A vertente a, por sua vez, denominada como de intenção de ruptura, não se apresenta, em hipótese alguma, homogeneamente. Marx, e sua tradição, orientam o debate desta tradição no interior do Serviço Social brasileiro, ainda que seja necessário destacar que as leituras sobre este legado não são consensuais, muito menos sua apreensão mediada pelo Serviço Social'. Nelas, todavia, as refrações da questão social são explicadas com base na "Lei Geral da Acumulação Capitalista" (MARX, 1984, p. 187). Trata-se de formar intelectuais comprometidos com um resgate refinado das produções marxianas (na sua totalidade e no seu tempo) e de parte de sua melhor tradição já presente no Serviço Social brasileiro: Lenin (2008), Lukács (1981; 2010; 2012; 2013), Gramsci (2000; 2007a; 2007b) e Mészáros (2002), além de uma tradição brasileira marxista de qualidade em que Caio Prado (2000; 2014), Octavio Ianni (1981) e Florestan Fernandes (1987 e 2009) são apenas exemplos. Para este grupo é preciso conhecer e debater as teses defendidas por outras tendências dentro e fora do Serviço Social, criticando leituras endógenas e relativistas, limitadas às verdades produzidas por olhares parciais iluminados pelas teorias do conhecimento, sem diminuir a importância da autocrítica. Por isto, a priori- 
dade ontológica das determinações materiais orienta a formação denominada por Netto como intelectuais. É neste contexto que a relação teoria e prática, como práxis, profissional ou social, adquire densidade, a teoria é reconstrução e não construção, muito menos aplicação, os profíssionais de Serviço Social não são técnicos operativos, mas sujeitos possíveis limitados por condições objetivamente dadas mediadas pelas profissões e por seus espaços sócio ocupacionais.

Formar intelectuais, conhecer e perseguir o movimento do real são iniciativas essências para uma leitura correta da realidade, bem como para formular alternativas capazes de fomentar espaços de contraofensiva e resistência profissional também no âmbito dos órgãos de defesa da categoria: o conjunto CFESS-CRESS, ABEPSS e ENESSO. O profissional, então, tensiona o espaço institucional sem negá-lo, valoriza a apropriação crítica e plural da teoria, não descarta o debate entre os diferentes, necessário à crítica radical, mas não aceita a justaposição pragmática e utilitarista deles (SIL VA, 2013; GUERRA, 2013). A relação da profissão com partidos e movimentos sociais libertários é essencial, mas não se identifica com eles (SIL VA, 2015; 2013). Nesta tendência duas grandes linhas são predominantes: 1) a primeira defende a afirmação e a defesa de direitos como espaço estratégico e de acúmulo de forças sociais daqueles segmentos que vivem da venda da força de trabalho (ANTUNES, 1999), tendo a emancipação humana como horizonte sem descartar níveis crescentes de emancipação política (MARX, 2009), visto o Serviço Social como profissão tendo o trabalho útilconcreto como categoria fundante do ser social na ordem burguesa e o trabalho alienado-estranhado a dimensão a ser criticada e superada. É neste contexto que a crítica ao capitalismo e ao capital é realizada enfatizando a necessidade de eliminar a desigualdade de classe própria da ordem em curso, bem como superar outras formas de opressões e de desigualdades objetivadas nesta sociabilidade. Em outras palavras, faz a crítica à ordem do capital sem desconsiderar um papel progressista, ainda que relativo e não etapista, do Serviço Social como profissão, das reformas progressistas e da defesa de direitos. As contribuições de Antonio Gramsci são aqui densamente recuperadas. 2)A segunda orientação no interior do projeto de ruptura endossa por completo a crítica à sociedade do capital e o compromisso com a emancipação humana. Põe em dúvida, no entanto, e isto a difere de sua coirmã, a possível contribuição que a afirmação de direitos, a profissão e as reformas sociais progressistas poderiam oferecer aos processos de ruptura com a ordem burguesa a partir de suas contradições objetivamente dadas. Nesta subtendência o legado gramsciano não tende a ser considerado como relevante e útil no interior da tradição marxista.

Mas o que está em jogo aqui nesta vertente comprometida com a crítica radical ao capitalismo e ao capital, portanto, à propriedade privada? Em relação à sua primeira subtendência o desafio se objetiva no sentido de atuar sobre uma contradição objetivamente dada: defender níveis crescentes de emancipação política, como espaço de acumulação de forças, tendo como horizonte a emancipação humana, em um contexto extremamente regressivo que renasce não apenas revelando a decadência social-liberal e neodesenvolvimentista, mas também mostrando todas as suas armas contra Marx e sua tradição. Mais do que isto, como defender direitos sem uma recaída neoconservadora que termine defendendo direitos precários e graduais em tempos de destruição de direitos universais?

Com relação à segunda subtendência que forma a vertente de intenção de ruptura, o desafio está em não distanciar-se das bases da profissão subestimando ou anulando sua importância, ainda que ela seja, claro, relativa. Este distanciamento seguramente provocará, e já vem provocando, uma desconexão completa dos desafios reais postos aos profissionais de Serviço Social no âmbito do trabalho profissional e, ao mesmo tempo, o que é pior, uma incapacidade significativa de contribuir com respostas às demandas a eles impostas. Nunca é demais recordar as observações de NETTO (1996, p. 126) relacionadas aos problemas a serem enfrentados pela vertente de intenção de ruptura: "muito do futuro desta vertente está hipotecado ao trato que vier a dar às demandas do mercado de trabalho". Isto não significa, em absoluto, que somente as demandas profissionais e os temas diretamente relacionados a ela devam compor os estudos profissionais, como se eles fossem os únicos e os mais legítimos (MONTAÑO, 2007). Mas é preciso alertar que o debate com a profissão, com os profissionais e com o mercado de trabalho dos assistentes sociais deve compor o conjunto de preocupações dos segmentos mais progressistas da profissão. Seguramente existem diversas formas e alternativas, não endógenas, que poderão alimentar essa aproximação.

\section{Comentários inconclusivos}

O legado de Gramsci para o Serviço Social brasileiro é útil e necessário. Oferece bases importantes, ainda que insuficientes, para a crítica aos reacionarismos, conservadorismos e aos neoconservadorismos em curso e à sua diversa fundamentação teórica. $\mathrm{O}$ resgate refinado de Marx e de sua densa tradição e o debate crítico-fraterno entre estas orientações é procedimento necessário para a reorganização e sobrevi- 
vência do legado crítico construído nos últimos 40 anos no interior desta profissão. Mais do que isto, conhecer e debater as teses dos reacionarismos e dos conservadorismos, mais ou menos renovados, e propor alternativas reais a elas é procedimento necessário à crítica radical, seja como práxis social ou como práxis profissional. Todavia, todo cuidado é pouco. É preciso cultivar a apreensão da obra gramscina na sua totalidade, em seu contexto histórico, não perdendo de vista que o Serviço Social é apenas uma profissão. Forcejar na direção de estimular a criação de assistentes sociais intelectuais não significa, em hipótese alguma, ajustar mecanicamente as noções gramscianas de intelectuais orgânicos e tradicionais, sobretudo a primeira, ao Serviço Social reeditando níveis perigosos de messianismo. Afirmar a atual direção social estratégica conhecida pela categoria dos assistentes sociais como Projeto Ético-Político Profissional exige, ao mesmo tempo, densidade analítica e ações coletivas concretas e propositivas. É preciso cultivar o otimismo da vontade sem abdicar do pessimismo da razão, procedimento que exige realismo e concretude nas análises sócio-históricas empreendidas.A influência mais promissora de Gramsci no Serviço Social brasileiro vincula-se, seguramente, à perspectiva de intenção de ruptura, especificamente aquela que vê insuficiência, mas pertinência e valor no campo da emancipação política. Não estimula, por isto, etapismos e gradualismos que perdem de vista a crítica radical ao capital e ao capitalismo, mas não subestima esta esfera mesmo nos duros tempos marcados pela precarização e redução brutal de direitos. É preciso, ao mesmo tempo, combater leituras ecléticas e fragmentadas que também têm afrontado a densa obra gramsciana, bem como simplificações nada afeitas ao autor.

\section{Referências}

ANTUNES, R. Adeus ao trabalho? Ensaios sobre as metamorfoses e a centralidade do mundo do trabalho . São Paulo: Cortez; Campinas: UNICAMP, 1999.

BARROCO, M. L. S. Barbárie e neoconservadorismo: os desafios do projeto ético-político.Serv. Soc. Soc. [online]. 2011, n.106, pp. 205-218. ISSN 0101-6628.

BECK, U. La sociedad del riesgo: hacia una nueva modernidad Barcelona: Paidós, 1998.

BERTALANFFY, L. V. Teoría general de los sistemas. México: Fondo de Cultura Económica, 1980.

BAUDRILLARD, Jean. A sociedade de consumo. Portugal: Edições 70, 2008.

BOURDIEU, P. O Poder Simbólico. Rio de Janeiro: Bertrand Brasil, 1992.

BRAZ, M.; RODRIGUES, M. O ensino em Serviço Social na Era Neoliberal (1990-2010)Sociabilidade Burguesa e Serviço Social. Rio de Janeiro: Lumen Juris, p. 255-281, 2013.

CAPRA, F. O ponto de mutação - a ciência, a sociedade e a cultura emegente. São Paulo: Editora Cultrix, 2004.

CASTEL, R. As metamorfoses da questão social: uma crônica do salário. Petrópolis: Vozes, 1998.

DERRIDA, J. Margens da Filosofia. Campinas: Papirus, 1991.

FERNANDES, F. A revolução burguesa no Brasil: ensaio de interpretação sociológica. Rio de Janeiro: Guanabara, 1987. . Capitalismo dependente e classes sociais na América Latina. São Paulo: Global Editora, 2009.

FOUCAULT, M. Microfísica do poder. Rio de Janeiro: Graal, 1993. . Vigiar e punir: história da violência nas prisões. Petrópolis: Vozes, 1994.

GUERRA, Y. Expressões do pragmatismo no Serviço Social: reflexões preliminares. Florianópolis: Revista Katálysis, v. 16, n. esp., p. 39-49, 2013.

GRAMSCI, A. Cadernos do cárcere. Os intelectuais. O princípio educativo. Jornalismo. Rio de Janeiro, volume 2, 2000. . Cadernos do cárcere. Maquiavel. Notas sobre Estado e a Política. Rio de Janeiro, volume 3, 2007a.

. Cadernos do cárcere. Temas de cultura. Ação católica. Americanismo. Fordismo. Rio de Janeiro, volume 4, 2007b.

IAMAMOTO, M. V. Serviço Social em tempo de capital fetiche - capital financeiro, trabalho e questão social. São Paulo: Cortez Editora, 2007.

; CARVAlHO, R. de. Relações Sociais e Serviço Social no Brasil. Esboço de uma interpretação histórico-metodológica. São Paulo: Cortez, 1985.

IANNI, O. A ditadura do grande capital. São Paulo: Civilização Brasileira, 1981.

LENIN, V. I. O imperialismo - fase superior do capitalismo. Tradução de Leila Prado. São Paulo: Centauro, 2008.

LYOTARD, F. A condição pós-moderna. Rio de Janeiro: José Olympio, 2000.

LUKÁCS, G. LUKÁCS. Organizado por José Paulo Netto. São Paulo: Ática, 1981. (Grandes cientistas sociais)

. Para uma ontologia do ser social I. São Paulo: Boitempo Editorial, 2012.

. Para uma ontologia do ser social II. São Paulo: Boitempo Editorial, 2013.

. Prolegômenos para uma ontologia do ser social. São Paulo: Boitempo Editorial, 2010.

MARX, K. Crítica da filosofia do direito de Hegel. São Paulo: Boitempo, 2005. . O capital: crítica da Economia Política São Paulo:Abril Cultural, 1983. v.1. 1.1. t.1. 
O capital: crítica da Economia Política São Paulo:Abril Cultural, 1984. v.1. L.1. t2.

O método da economia política. In: FERNANDES, F. (Org.). In: Marx e Engels: História. São Paulo: Ática, 1989. (Textos originais de Marx e Engels).

. Para a questão judaica. São Paulo: expressão Popular, 2009.

MAFFESOLI, M. O instante eterno: o retorno no trágico nas sociedades pós-modernas. São Paulo, Zouk, 2003.

O ritmo da vida: variações sobre o imaginário pós-moderno. Rio de Janeiro, Record, 2007.

MERTON, R. K. Sociologia: Teoria e estrutura. São Paulo: Mestre Jou, 1968.

MÉSZÁROS. I. Para além do capital. São Paulo: Boitempo, 2002.

MONTAÑO, C. A natureza do Serviço Social: um ensaio sobre sua gênese, a "especificidade" e sua reprodução. São Paulo: Cortez, 2007.

MORIN, E. Introdução ao pensamento complexo. Porto Alegre: Editora Sulina, 2015.

NETTO, J. P. Capitalismo monopolista e Serviço Social. São Paulo: Cortez, 1992.

. Ditadura e Serviço Social: uma análise do Serviço Social no Brasil pós-64 São Paulo: Cortez, 1991.

. Transformações societárias e Serviço Social: notas para uma análise prospectiva da profissão no Brasil. Serviço Social \& Sociedade. São Paulo: Cortez, n. 50, p. 87-132, abr. 1996.

PARSONS, T. A estrutura da ação social: Marshal, Pareto e Durkheim. São Paulo: Vozes, v1, 2010. . A estrutura da ação social. Weber. São Paulo: Vozes, v2, 2011.

PRADO JUNIOR, C. A revolução brasileira: a questão agrária no Brasil. São Paulo: Companhia das Letras, 2014. . Formação do Brasil contemporâneo. São Paulo: Brasiliense; Publifolha, 2000.

ROSANVALLON, P. La nueva cuestión social: repensando el Estado Providencia. Buenos Aires: Manantial, 1995.

SANTOS, B. S. Pela mão de Alice: o social e o político na pós-modernidade. São Paulo: Cortez, 1992.

SEN, A. K. Desenvolvimento como liberdade. São Paulo: Companhia das Letras, 1999.

SILVA, J. F. S. Crise do capital, neoconservadorismo e Serviço Social no Brasil: apontamentos para o debatRevista Em Pauta. Rio de Janeiro: UERJ, n. 35, v. 13, p. 99 - 125, 2015,

Serviço Social: resistência e emancipação? São Paulo: Cortez, 2013.

Sociedade do capital,América Latina e Serviço Social: contribuição brasileira ao debateIn: SILVA, J. F. S. da; GUTIÉRREZ,T.

Política Social e Serviço Social: Brasil e Cuba em debate São Paulo, Veras Editora, 147-177, 2016.

WEBER, M. A “objetividade” do conhecimento nas ciências sociais. In: COHN, G., WEBER - sociologia. São Paulo: Ática, 79-127, 1986. (Coleção Grandes Cientistas Sociais 13).

\section{Notas}

1 Sobre o sentido atribuído à categoria da totalidade consultar Marx (1989).

2 Não é recente o debate sobre os conservadorismos e os neoconservadorismos no âmbito do Serviço Social brasileiro. Tecemos algumas observações sobre este tema em Silva $(2013 ; 2015 ; 2016)$. Parece oportuno destacar a necessidade de aprofundar os estudos já exsitentes sobre os conservadorismos e sua renovação, bem como empreender uma análise atual sobre o recrudescimento de tendências reacionárias partir das condições objetivamente dadas.

3 Estes últimos, por serem tradicionais, não perdem - obviamente - seu vínculo de classe.

4 O bloco histórico se consolida na luta concreta entre as classes e seus projetos na busca por hegemonia em um momento históripreciso.Articula organicamente a estrutura e a superestrutura, espaço em que os intelectuais exercem um papel importante.

5 De nossa parte não há como esclarecê-la desconsiderando a Lei Geral daAcumulação Capitalista (MARX, 1984) que, sem qualquer oncessão economicista, está vinculada às condições objetivamente dadas para que o ser social se reproduza como tal na ordem em cursdbarguesa. O ser social é, ao mesmo tempo, classe e indivíduo. Isto significa que as refrações da questão social se objetivam neste ser na suatalidade.

6 O Consenso ou o Pós-consenso de Washington estabelece como paradigma para a América Latina e para outras regiões do planeta di tas emergentes, a estabilidade macroeconômica e o crescimento dinamizado por meio das exportações. Institui a tríade maldita: o serávit primário, os juros altos e o câmbio flutuante.

7 Destrinchados em conceitos tais como função manifesta e função latente (MER TON, 1968); evolução de sistemas, adaptação, subsis temas funcionais (TALCOTT PARSONS, 2010; 2011).

8 Não se trata, aqui, de negar a importância das especificidades e dos microespaços, mas de salientar criticamente a sua incapłade como instâncias em si, fragmentadas.

9 É preciso reconhecer a diversidade destes autores, suas heterogêneas trajetórias, bem como suas diferenças analítico-qualitativas. Existe neles, todavia, um fio condutor: a crítica aos paradigmas e às metanarrativas da modernidade.

10 Único nível possível para o plano do conhecimento, já que a dimensão objetiva, sua lógica como lógica da coisa é, para Kanimpenetrável.

11 O recente debate sobre o Serviço Social ser ou não ser trabalho, protagonizados por Lessa e Iamamoto (2007), ou as diferençasntre Netto e a mesma Iamamoto sobre a tese do sincretismo da prática indiferenciada no Serviço Social, expressa tais divergências ertre várias coincidências. 


\section{José Fernando Siqueira da Silva}

jfernandoss@terra.com.br

Doutor em Serviço Social pela Pontifícia Universidade Católica (PUC).

Professor do Departamento de Serviço Social da UNESP-Franca.

\section{UNESP - Faculdade de História, Direito e Serviço Social de Franca}

Av. Eufrásia Monteiro Petráglia, 900 - sala 35

Jardim Dr. Antonio Petráglia

Franca - São Paulo - Brasil

CEP: $14409-160$

\section{ERRATA}

No artigo "Serviço Social e tendências teóricas atuais" de José Fernando Siqueira da Silva, com número de DOI: 10.1590/1414-49802017.00100008, publicado no periódicoRevista Katálysis, v.20, n. 1, jan./abr. \17, na página 65 , no resumo:

Onde se lia:

"O artigo propõe um o debate sobre as atuais tendências teórico-metodológicas do Serviço Social brasileiro"

Leia-se:

"O artigo propõe um debate sobre as atuais tendências teórico-metodológicas do Serviço Social brasileiro" 